Ansio Martínez, Tania.

Doctoranda en Arte: Producción e Investigación. Universidad Politécnica de Valencia.

\title{
La deriva gráfica con el grabado a la deriva.
}

\section{Contemporary graphic art drift with the drifting engraving.}

TIPO DE TRABAJO:

Comunicación.

PALABRAS CLAVE:

Investigación gráfica, gráfica contemporánea, grabado experimental, deriva gráfica.

KEY WORDS:

Graphic Research, contemporary graphic art, experimental printmaking, drifting engraving.

\section{RESUMEN.}

El artista gráfico trasmedia desde las diversas fases constitutivas del grabado: matriz, estampación e intervención sobre la estampación, hacia la fusión e integración de todas las artes. Continúa así la deriva, comenzada ya el siglo pasado, en la que el espíritu de la gráfica trasciende lo ortodoxo, transitando lo heterodoxo, en busca de su espacio en el arte como un medio de creación contemporáneo.

Si codificar significa repensar los códigos, los múltiples formatos gráficos, establecidos o de nueva aparición, y encontrar el modo de relacionarlos, la investigación se desprende no sólo desde un punto de vista formal sino semántico o poético, dentro de esta disciplina en constante fuga, y donde no es fácil ni siquiera reconocer hasta qué punto está implosionando o expandiéndose, y donde muchas veces (si esto fuera necesario o pertinente) es difícil discernir los límites del mismo término grabado. Esta gráfica fugada contemporánea posee una deriva entre la producción y la reflexión, en la convergencia entre tradición e innovación.

La investigación permite analizar las posibilidades de la gráfica para ocupar nuevos espacios y medios que posibilitan al espectador relacionarse con la obra en su totalidad háptica, con la renovación de los formatos expositivos y de las instalaciones.

Un profundo ejercicio crítico dentro de la investigación en Arte lleva a encontrar y relacionar el conocimiento personal con el enfoque global. Por eso otra línea de investigación son los centros de formación que considero están mostrando una vocación trasgresora de los límites académicos aceptados históricamente, para conectar el ámbito académico con el social y el investigador con el productor.

Recabar la información del estado de la cuestión en los espacios y la docencia actual nos permitirá aportar a la sociedad un mapa de la realidad social y formativa que podemos encontrar actualmente en esta deriva gráfica.

\section{ABSTRACT.}

The graphic artist transmoves from the different constitutive stages of the printmarking -matrix, printing and intervention over the printing- towards de fusion and integration of all the arts. In this way, the drift, which already started last century, goes on; in it, the spirit of graphic art goes beyond the orthodox fact, passing through the unorthodox one, searching for its own place in art as a contemporary means of creation. 
If recoding means to rethink the codes, the numerous graphic formats, the established ones or those newly birth, and finding the way of conneting them, the research becomes deduced not only from a formal point of view, but also from a semantic or a poetic one, within this discipline in continuous escape, where it is not easy even to realise to what extent it is imploding or expanding, and where it is often difficult -if this was necessary or relevant- to distinguish the limits of the very engraved element itself. This contemporary escaped graphic art owns a drift between the production and the reflection, in the convergence between tradition and innovation.

Researching allows us to analyse the possibilities of graphic art to take up new spaces and means which enable the spectator to connect with the work in its haptic entirety, with the renovation of the exhibition formats and facilities.

A deep critical exercise within the research in Arts leads us to find and connect the personal knowledge with the global point of view. That is why another researching line is that of the educational centres, which I consider to be showing a vocation to transgress the historically accepted academic limits in order to connect the academic field with the social one and the researcher with the producer.

Collecting información about the matter state in the current spaces and teaching will allow us to bring to society a map of social and formative reality which we can find at present in this graphic art drift.

\section{CONTENIDO.}

\section{INTRODUCCIÓN.}

Hace unos 6 años en los estudios de Licenciatura de la Facultat de Belles Arts de Valencia, descubrí los procesos del grabado y me enamoré del medio. También escuché por primera vez el término Gráfica Expandida, sin comprender exactamente a qué se refería ni qué abarcaba, aunque entendí que supone un proceso vivo de experimentación, que enarbola la transversalidad y el reconocimiento del lenguaje gráfico como un medio de creación y de comunicación.

Desde el mundo de la escultura, del que yo provengo, había leído los escritos de Rosalind Kraus (1985) y de Maderuelo (1994) por lo que nociones como Escultura de campo Expandido y Pérdida del pedestal, asimilado a la pérdida de las nociones clásicamente aceptadas, no me eran desconocidas.

Supuse así que este proceso aplicado al grabado sería algo similar, y que, conforme fuera aumentando mi conocimiento del medio, podría igualmente ir ampliando y comprendiendo los conceptos.

Pero en el mundo de la gráfica esto no es así. Teoría y praxis no van parejas. Existe un desajuste entre la experiencia local (del taller, de los centros de formación, de las innovaciones que realizan los grabadores de forma independiente y disgregada...) y el desarrollo, prácticamente inabarcable, de la gráfica en su globalidad de manifestaciones. No podemos olvidar que el grabado se ha enriquecido constantemente de la investigación de los artistas, que han ido experimentando y asimilando nuevas técnicas. Coincidimos con Martínez Moro (1998) en que el grabado "no puede pertenecer al sistema de las verdades últimas y definitivas, sino al del ensayo, la experimentación y la posibilidad".

En nuestra sociedad y con los medios actuales, eso supone un cambio de paradigma, una inmediatez en la globalización que hace que el trabajo en el terreno local se disgregue, permanezca muchas veces con pequeñas redes relacionales, por lo que el artista, en tanto que investigador, debe abrirse a cuanto le rodea, trascender lo ortodoxo, transitar lo heterodoxo y buscar su espacio en el arte contemporáneo, repensar los códigos para recorrer ese camino bidimensional que circula desde lo local a lo global.

\section{DESARROLLO.}

Desde los años 60 se están renovando conceptualmente los discursos gráficos. Esto es posible por la transversalidad de la investigación de múltiples artistas que trabajan desde la transferencia técnica entre disciplinas y el mestizaje de medios, en expansión de conceptos, materiales, procesos y procedimientos.

En cuanto a su relación con la cultura y la repercusión social que supone la gráfica, por su posibilidad de creación y difusión de imágenes, los tradicionales medios de estampación y los nuevos medios de impresión y reproducción, favorecen su interacción con otras disciplinas y su expansión. 


\author{
Ansio Martínez, Tania \\ La deriva gráfica con el grabado a la deriva \\ III CONGRESO INTERNACIONAL DE INVESTIGACIÓN EN ARTES VISUALES :: ANIAV 2017 :: GLOCAL [codificar, mediar, transformar, vivir] \\ http://dx.doi.org/10.4995/ANIAV.2017.4859
}

No hay más que ver la multitud de Foros, Encuentros, Congresos, que pretenden dar una normatividad a estas manifestaciones de difícil catalogación, en las que se busca muchas veces crear una pieza única, más que su posible reproducción. Así se está hablando de la gráfica virtual, la gráfica expandida, la gráfica intangible, el arte múltiple, la obra gráfica seriable, la gráfica radicante...

Muchos de estos conceptos fueron recogidos en las Actas del Primer Foro de Arte Múltiple ii celebrado en 2011 en Madrid simultáneo a Estampa, Feria Internacional de Arte Múltiple Contemporáneo. A través de las distintas ponencias se hace un repaso exhaustivo de las preocupaciones de los artistas investigadores en torno al tema de la reproductibilidad técnica; la normalización o no del grabado; de su aceptación o no dentro de unos límites; y de la ruptura de éstos y de la interdisciplinariedad que esta disciplina permite.

Distintas Escuelas de Arte, Universidades, Centros de Investigación, Equipos y Talleres por todo el mundo, están trabajando con este concepto desde la idea del hecho gráfico como medio de expresión y la conceptualización de original y múltiple como valores identificativos de la obra gráfica, atendiendo a la interacción existente entre las diferentes disciplinas artísticas. Esta investigación requiere un análisis profundo del carácter específico del grabado, desde su ubicación histórica en el mundo del Arte, con amplitud de miras. Trabas para esta renovación surgen desde este mismo campo, en posiciones academicistas que intentan reivindicar como grabado únicamente aquel que responde a los estrictos criterios normativos que cimentaron su valor durante años. Ahora no pueden representar la realidad del arte actual que vive una renovación y expansión en la que, como hizo Maderuelo en la escultura, quizás hay que negar alguno de sus fundamentos primarios.

Una visión reduccionista del grabado busca su valoración desde sus propios parámetros específicos y concretos, es decir, "desde sí mismo", iii con sus normas consensuadas y asumidas por artistas y público, considerando sólo su función reproductiva. Porque, a pesar de estar "permanentemente a la vanguardia de los desarrollos tecnológicos y formar parte indiscutible de la industria de la imaginería social,"iv durante décadas ha permanecido en los límites del espacio del arte, como dice Concha García Sánchez.

Aunque la investigación gráfica es generalizada, me interesa analizar cómo algunas Universidades y Escuelas de Grabado en España (Valencia, Barcelona, Salamanca, Madrid, Cantabria, País Vasco, Vigo) y América latina (Argentina y México), de amplia tradición gráfica, están investigando y experimentando distintas incursiones en la distensión de los límites de la gráfica, para realizar un análisis formal y semántico, dentro de esta disciplina en constante fuga. La gráfica contemporánea posee una deriva entre la producción y la reflexión, en la convergencia entre tradición e innovación, sobre la que se ha escrito y discutido ya mucho, pero que no cesa de evolucionar y manifestarse multimodalmente.

\title{
TRANSMEDIA Y EVOLUCIÓN.
}

La mentalidad de nuestro tiempo, y el arte como producto de éste, está marcada por la codificación: de conocimientos, de comunicaciones, de medios y lenguajes, de relaciones intertextuales, de técnicas o de operaciones.

Ya en 1855, el crítico de arte Théophile Thoré hablaba del advenimiento de una sociedad y un arte nuevo que traía la universalidad viendo que: "(...) un telégrafo invisible transmite instantáneamente los sucesos e ideas de un extremo al otro del globo, los pueblos abren sus fronteras y una nueva generación viaja, aprende lenguas, estudia otras culturas. La humanidad está en trance de constituirse y cobrar conciencia de sí." Esta construcción enriquece la investigación y experimentación. ${ }^{\vee}$

El análisis sociológico que realizó hace ya unos años Omar Calabrese (1987) en La Era Neobarroca, de los cruces entre lo que denomina alta y baja cultura, afecta a la forma en que son aceptados y compartidos los códigos, pues plantea que estos entrecruzamientos van desde la ciencia a los medios de comunicación, de la literatura a la filosofía y del arte a los comportamientos cotidianos. Porque de lo que se trata es de un profundo cambio en la estética de la vida contemporánea por la simbiosis entre el arte y la comunicación de masas, relacionando los comportamientos locales con la esfera global. El arte se trasforma mientras trasforma los códigos de los distintos medios en que es empleado.

La gráfica como medio de creación con autonomía propia conjuga los sistemas de creación tradicionales, las herramientas tecnológicas, visuales y audiovisuales, y los recursos de otras disciplinas. La información se distribuye con los medios de comunicación de masas a una velocidad vertiginosa, y el conocimiento circula de forma masiva y se nutre de las relaciones entre personas y máquinas de manera enriquecedora.

Observamos el grabado como un sistema, con capacidad de trasformación de una multitud de elementos: ideación, matriz, estampa, estampación o trasferencia a un soporte, serie, repetición, acabado, postproducción.

López Izquierdo (2006) identifica las fases de elaboración de la matriz, fases que constituyen la estampación y fases de intervención directa sobre la estampación.. Cualquiera de ellas puede expandirse y multiplicar su valor fácilmente. 
En el libro de Mínguez (2012) Gráfica contemporánea. Del elogio de la materia a la gráfica intangible encontramos un abanico de ejemplos de artistas en su multiplicidad.

La investigación y experimentación evoluciona desde su capacidad de relación con otros medios. Natalia Matewecki, en su artículo Hibridaciones visibles e invisibles en arte y medios, dice: "Si bien el concepto de hibridación no es nuevo, se retoma en la contemporaneidad debido a la pluralidad de voces que dialogan simultáneamente en una obra artística, un texto literario, un desarrollo científico o un medio de comunicación. "vi

Las posibilidades de la gráfica como medio de comunicación y su evidente transversalidad con lo público, genera actividad en aspectos relativos a la repercusión social desde el ámbito de creación y difusión de imágenes, con tecnologías tradicionales o nuevos sistemas de impresión; a través de procesos alternativos y con la facilidad para ocupar nuevos espacios y medios, que posibilitan al espectador interactuar con la obra en su totalidad háptica; con la renovación de los formatos expositivos, su participación en instalaciones o las nuevas estrategias de gestión gráfica que permiten los libros de artista o edición combinada de arte.

Aunque la diversidad pueda parecer una pérdida de los límites históricamente reconocidos del Grabado desde su concepción más tradicionalista, paradójicamente, es lo que permite ampliar su concepto. Le acerca a la realidad múltiple de los artistas que están creando actualmente su obra sustentados en la mezcla aleatoria de ideas o procedimientos, trasmitiendo nuevos modos mixtos de trabajar desde distintas perspectivas, o investigando las fronteras de una disciplina que desde sus posibilidades reproductivas o reproductibles, responde a la realidad actual.

La gráfica siempre ha sido un terreno conceptualmente experimental y de investigación. Históricamente ha heredado los importantes avances técnicos del mundo industrial, apropiándolos a su quehacer artístico y aplicándolos creativamente, como sucedió con la imprenta, la litografía, la serigrafía, la estampación digital, etcétera. Técnicas que surgieron como una potencialidad, son integradas con toda su riqueza. Lo que en su momento supuso una revolución, se asimila como una herramienta más de trabajo.

Somos artistas que vivimos nuestro tiempo y aprovechamos todo lo que nos ofrece el cambio en el modo de hacer las imágenes. De hecho, dice Vanesa Gallardo Fernández que, como creadores: "No debemos despreciar el progreso, sino unirnos al mismo para enriquecer nuestro proceso creativo." vii Hoy, comenta, se produce un cambio en nuestra forma de mirar, estamos inmersos en una realidad visual en que la vista llega antes que las palabras; y esto altera el modo de hacer las imágenes y disuelve los límites entre las disciplinas artísticas. Los códigos evolucionan y el artista se sirve de ello.

\section{DESDE EL ORDENADOR HASTA EL INFINITO.}

Al hablar de la variación en la gráfica, no olvidamos los medios de producción de imágenes de naturaleza digital, que comparten características con los medios tradicionales. Ya en el constructivismo ruso fotomontadores como Rodchenko o El Lissitzky, hablaban de Poligrafía para definir sus creaciones pseudo-fotográficas, fusión entre fotografía, collage, diseño y tipografía, con impresión fotomecánica.

Jaime Munáriz habla de las posibilidades que ofrece el arte digital en la creación de "variaciones, mutaciones, mezclas y superposiciones". viii Lo visual y lo audiovisual interrelacionados, sacando partido de la multiplicidad del medio.

El mundo digital amplía de tal manera el abanico de recursos que, como comenta Bernat, todo parece complicarse con los medios informáticos para la creación: "Las prensas offset, las máquinas de fotocopiar, los trazados por ordenador, las matrices intangibles, incluso las redes sociales como matriz seducen cada vez más a los creadores dotando de ubicuidad y atemporalidad muchas creaciones. Hoy en día, gracias a esa inmaterialidad y reproductibilidad virtual, cada visionado es un ejemplar más. "ix

Manovich define la mezcla de medios gráficos que conforman un metamedium. "Lo que se remixa hoy no es sólo el contenido de los diferentes medios, sino fundamentalmente sus técnicas, sus métodos de trabajo y las formas de representación y de expresión. Unidos por el entorno común del software, el cine, la animación, la animación por computadora, los efectos especiales, el diseño gráfico y las tipografías han llegado a formar un nuevo metamedium (metamedio). Una obra producida en este nuevo metamedio puede usar todas las técnicas, o cualquier subconjunto de ellas, cuando antes, pertenecían exclusivamente a cada uno de esos medios."

Con Brea (2006) compartimos la idea de un cambio en la forma de abordaje de las prácticas de producción de significado y su propuesta de fusión entre disciplinas: "Se trata en ello de moverse a ritmo de $n+1$, poniendo a prueba cada acoplamiento, cada ensamblaje, cada agregación posible. No de descartar nada, no de negar nada, sino de asegurar el máximo de riqueza y densidad conceptual en la mirada analítica que escruta y valora"

Aunque hoy nos parezca natural, no hace ni 20 años de la primera exposición en España (1998) de La Estampa Digital en la Calcografía Nacional, que englobó propuestas generadas por medios digitales y nuevas técnicas de impresión. Gómez Isla contaba: “En aquel 
momento, tuvimos la sensación de estar asistiendo a un mestizaje singular entre disciplinas hasta entonces irreconciliables. Sin embargo, en esta muestra convivían sin aparentes conflictos medios tan dispares como el grabado tradicional, la infografía, la fotografía o incluso la propia escultura generada por ordenador. ${ }^{\prime x}$

\section{INVESTIGACIÓN Y EXPERIMENTACIÓN PROPIA.}

Llevo varios años intentando comprender el alcance de esta forma amplia de reconocer la gráfica que se encuentra en un momento de incesante fluctuación, donde los parámetros varían constantemente y la dispersión global es inmensa. Pues frente a los sectores más conservadores, en otros se relega el valor artesanal y se aborda de muy distinta forma las prácticas de producción de significados y de distribución masiva.

Encontrar bibliografía sobre técnicas tradicionales es sencillo y abundante. Pero cuando se intenta analizar otras formas de entender el grabado desde un concepto más global, es cuando realmente viene la dificultad.

A la par, quiero investigar cómo se está experimentando en las asignaturas gráficas desde distintos ámbitos educativos, por ser lugares que están mostrando una vocación trasgresora. Analizar cómo se relaciona la enseñanza en arte con la realidad que luego van a encontrar los alumnos al enfrentarse al mundo real y si están facilitando conectar el ámbito académico con el social y el investigador con el productor.

He mostrado un recorrido por los planteamientos teóricos y prácticos del camino que llevo realizado en mi investigación doctoral y espero que la misma tenga un desarrollo posterior de vinculación de este conocimiento en una red de artistas y centros con un reconocimiento de intereses mutuos.

Simultáneamente estoy realizando una experimentación propia. Al profundizar en los conceptos, se despierta mi interés por ampliar la experimentación a muchas de las cosas que investigo. Trabajo con variación de los conceptos gráficos en distintas etapas de la producción gráfica (variación de matriz, soporte e intervención). Estoy estudiando para su registro una técnica que he denominado: Encapsulado de grabado calcográfico en polietileno termofundido, en la que participa material plástico de reciclaje como soporte alternativo, dotando de juegos de trasparencias y una cualidad vitral a la estampa así obtenida. Es un proceso innovador que, frente a la estampa en papel, aporta otras potencialidades volumétricas emanadas de su origen plástico, fundible y moldeable.

También participo activamente en asociaciones, centros y redes de artistas en torno a este modelo de gráfica que expande su territorio.

\section{CONCLUSIONES}

Con este profundo conocimiento del medio, coincido con muchos grabadores en que para trabajar en grabado, lo realmente importante es pensar en grabado: printmaking is a way of life.

A pesar del título de mi ponencia, considero que la deriva gráfica actual es un excelente campo de investigación teórica y experimental. No creo que el grabado se encuentre a la deriva, sino que saldrá fortalecido, siempre que sepa reconocer los códigos que le identifican y sea capaz de transitar entre ellos, desde la experimentación y la variación, desde lo local a lo global, integrando tantas posibilidades como artistas la practican.

\section{FUENTES REFERENCIALES.}

REFERENCIAS BIBLIOGRÁFICAS.

CALABRESE, OMAR. La era Neobarroca. Cátedra, Madrid, 1994 (1987, Roma)

COLDWELL, Paul. Printmaking. A contemporary perspective, Black dog Publishing, London 2010

CREMADES ALEGRE, Antonio., El grabado, técnicas y su repercusión, Cátedra, Valencia, 2006.

DAWSON, John, Guía completa de grabado e impresión: Técnicas y materiales, Blume, Madrid, 1996

GARRIDO SANCHEZ, Maㅡ Carmen. Grabado: procesos y tecnicas. Akal, Madrid, 2014 
GRABOWSKI, Beth, El grabado y la impresión: guía completa de técnicas, materiales y procesos. Blume, Barcelona, 2009

HERNÁNDEZ, Magali. Gráfica: aplicaciones alternativas y emergentes. Dirección de Extensión y Difusión Cultural, Chihuahua, México. 2010

HOWARD, Keith, The contemporary printmaker: intaglio-type and acrylic resist etching. Write-Cross Press, New York, 2003,

IRUJO ANDUEZA, Julián, La materia sensible: técnicas experimentales de pintura. Blume, Barcelona, 2008

IVINS, William M., Imagen impresa y conocimiento. Análisis de la imagen prefotográfica. Barcelona, 1975

KUSPIT, DONALD, en "Del arte analógico al arte digital, de la representación de los objetos a las codificación de las sensaciones". En Arte digital y Videoarte. Transgrediendo los límites de la representación. Círculo de Bellas Artes, Madrid, 2005

LEAF, Ruth, Etching, Engraving and Other Intaglio Printmaking Techniques (Dover Art Instruction). Dover Publications Inc., New York, 1984

LÓPEZ IZQUIERDO, M.A.: El grabado animado experimental: nuevas posibilidades de creación técnica y simulación estética. Editorial Universidad Politécnica de Valencia. Valencia, 2006.

MADERUELO, Javier. La pérdida del pedestal. Fundación de Cultura, Diputación Provincial de Huesca. Valladolid. 1994 .

MANOVICH, Lev, El lenguaje de los nuevos medios de comunicación. La imagen en la era digital., Paidós Comunicación, Barcelona, 2005

MARTIN, Judy, Enciclopedia de técnicas de impresión: Guía visual detallada de técnicas de impresión, acompañada de proyectos prácticos y de una inspirada galería de obras terminadas. Acanto, Barcelona, 1994

MARTÍNEZ MORO, Juan. Un ensayo sobre grabado (A finales del siglo XX), Creática, Santander, 1998

MARTÍNEZ MORO, Juan. Un ensayo sobre grabado (A principios del siglo XXI). Universidad Nacional Autónoma de México. México, 208. 183 pp. Santander, 1998

MÍNGUEZ, HORTENSIA: Gráfica contemporánea. Del elogio de la materia a la gráfica intangible, Universidad Autónoma de Ciudad Juárez. México 2012

NEWMAN, Thelma R. Innovative Printmaking. The making of two ¿and three? dimensional prints and multiples., Crown Publishers, New York 1977

NOYCE, Richard. Printmaking at the Edge, A\&C Black, London, 2006

RUBIO MARTÍNEZ, M. Ayer y hoy del grabado. Edic. Tarraco, Tarragona, 1979

WRIGHT, Michael, Introducción a las técnicas mixtas. Blume, Barcelona, 1996

\section{REFERENCIAS EN WEB.}

BERNAL PÉREZ, MARÍA DEL MAR. Técnicas de grabado [Blog Internet]. Consulta: 16 enero 2017 en http://tecnicasdegrabado.es/

BREA, JOSÉ LUIS (2006) Estética, Historia del Arte, Estudios visuales, Estudios visuales, 33. Consulta: 16 enero 2017 en http://estudiosvisuales.net/frevista/index,htm

ESTAMPA ARTE MÚLTIPLE, 19 Feria Internacional de Arte Múltiple Contemporáneo, libro de actas. Primer Foro de Arte Múltiple, Madrid 2011. Consulta: 16 enero 2017 en http://www.estampa.org/web/wp-

content/uploads/downloads/2012/12/Actas_Foro_AM.pdf 
GALLARDO FERNÁNDEZ, VANESSA: Gráfica Interdisciplinar. 9. Estampa Digital y Gráfica expandida. Consulta: 16 enero 2017 en http://ocw.usal.es/humanidades/lenguajes-alternativos-con-la-grafica

GARCÍA SÁNCHEZ, CONCEPCIÓN. TESIS DOCTORAL: Procesos de creación en técnicas mixtas a través de la xilografía. Consulta: 16 enero 2017 en http://eprints.ucm.es/15258/1/T33251.pdf

GÓMEZ ISLA, JOSÉ. Imagen Digital. Lecturas híbridas. Consulta: 16 enero 2017 en

http://pendientedemigracion.ucm.es/info/univfoto/num1/fhibridas.htm

MATEWECKI, NATALIA. Hibridaciones visibles e invisibles en arte y medios. Universidad de la plata- Facultad de Bellas Artes. Consulta: 16 enero 2017 en http://sedici.unlp.edu.ar/handle/10915/40562

RAMOS GUADIX, Juan Carlos, Técnicas Aditivas en el Grabado Contemporáneo. Universidad de Granada, 1992. Consulta 16 Enero 2017 en: http://digibug.ugr.es/handle/10481/14058

\footnotetext{
'Pérdida del pedestal y Campo expandido son términos con los que se enarbola la renovación en escultura por la cual se pierden los límites clásicamente establecidos. Se pierde el pedestal, la peana sobre la que se supone debería reposar una figura y se amplía el espacio físico que ocupa.

"Para quien tenga interés, es de lectura obligada, pues hace un repaso por muchos de los caminos de experimentación que se han producido y se siguen produciendo en los últimos años. Estampa Arte Múltiple, 19 Feria Internacional de Arte Múltiple Contemporáneo, libro de actas. Primer Foro de Arte Múltiple, Madrid 2011.

iii PASTOR, JESÚS. Sobre la identidad del grabado. En Actas Primer Foro de Arte Múltiple, Madrid 2011.

iv TESIS DOCTORAL de CONCEPCIÓN GARCÍA SÁNCHEZ: Procesos de creación en técnicas mixtas a través de la xilografía.

"KUSPIT, DONALD, en "Del arte analógico al arte digital, de la representación de los objetos a las codificación de las sensaciones". En Arte digital y Videoarte. Transgrediendo los límites de la representación. Círculo de Bellas Artes, Madrid, 2005

vi En MATEWECKI, NATALIA. Hibridaciones visibles e invisibles en arte y medios. Universidad de la plata- Facultad de Bellas Artes.

vii GALLARDO FERNÁNDEZ, VANESSA: Gráfica Interdisciplinar. 9. Estampa Digital y Gráfica expandida.

viii MUNÁRIZ, JAIME. Arte digital como múltiple. En Actas Primer Foro de Arte Múltiple, Madrid, 2011.

ix BERNAL PÉREZ, MARÍA DEL MAR. Técnicas de grabado [Blog Internet].

× GÓMEZ ISLA, JOSÉ. Imagen Digital. Lecturas híbridas.
} 